\title{
A systematic review and meta-analysis on influencing factors of failure of oral implant restoration treatment
}

\author{
Bo Lu, Xu Zhang, Binghao Liu \\ Department of Stomatology 2, The Fourth Clinical College of Xinxiang Medical University, Xinxiang, China \\ Contributions: (I) Conception and design: B Lu, B Liu; (II) Administrative support: B Lu; (III) Provision of study materials or patients: B Lu, X Zhang; \\ (IV) Collection and assembly of data: All authors; (V) Data analysis and interpretation: All authors; (VI) Manuscript writing: All authors; (VII) Final \\ approval of manuscript: All authors. \\ Correspondence to: Binghao Liu. Department of Stomatology 2, The Fourth Clinical College of Xinxiang Medical University, 56 Jinsui Avenue, \\ Xinxiang 453003, China. Email: 1bh_doctor@163.com.
}

\begin{abstract}
Background: With the continuous improvement of human living standards, more and more dental patients are requiring oral implant restoration treatment. However, there is still controversy regarding the influence of risk factors such as osteoporosis, radiotherapy, diabetes, and smoking on the failure of oral implants. This study aimed to explore the correlation between risk factors and failure of oral implant restoration treatment.

Methods: The databases of China National Knowledge Infrastructure (CNKI), Baidu Academic, Weipu, Wanfang, PubMed, EBSCO, Medline, Web of knowledge, Ovid, and the Cochrane Library were searched. The search strategies included: subject terms related to research results such as survival, osseointegration, failure, removal, replacement, and loss; related to risk factors: osteoporosis, head and neck cancer, diabetes, and smoking; and oral implantology as a keyword.
\end{abstract}

Results: Thirty-two articles were included in meta-analysis, there was a high heterogeneity between radiotherapy and dental implant failure $\left(\mathrm{I}^{2}=71.6 \%, \mathrm{P}=0.000\right)$, and there was an obvious correlation between radiotherapy and dental implant failure [relative risk $(\mathrm{RR})=2.09,95 \%$ confidential interval (CI): 1.68-2.61]. There was heterogeneity between diabetes and oral implant failure in the included articles $\left(\mathrm{I}^{2}=59.6 \%\right.$, $\mathrm{P}=0.084)$. There was no remarkable correlation between osteoporosis and dental implant failure $(\mathrm{RR}=1.19$, 95\% CI: 0.81-1.74). There was a high heterogeneity between smoking and dental implant failure in the included articles $\left(\mathrm{I}^{2}=33.8 \%, \mathrm{P}=0.092\right)$, showing obvious correlation ( $\left.\mathrm{RR}=1.80,95 \% \mathrm{CI}: 1.53-2.11\right)$.

Discussion: The results of meta-analysis confirmed that radiotherapy and smoking were greatly associated with oral implant failure.

Keywords: Failure of oral implants; influencing factors; meta-analysis

Submitted Nov 02, 2021. Accepted for publication Dec 17, 2021.

doi: 10.21037/apm-21-3449

View this article at: https://dx.doi.org/10.21037/apm-21-3449

\section{Introduction}

In the past 10 years, with the improvement of medical standards, dental implants have been increasingly clinically used to repair missing teeth (1). Compared with traditional restoration techniques, implant restoration has the advantages of no damage to adjacent teeth, strong chewing load function, and high comfort, which has led to increased patient acceptance (2). According to research reports, the 5-year survival rate and ten-year survival rate of oral implants are $97 \%$ and $90 \%$, respectively. However, implantation failures due to implant shedding still exist (3).

With the continuous development of implant materials and implant surgery technology, the current dental implants can obtain good osseointegration, and the bone supports the implant crown to bear occlusal pressure. However, it is worth paying attention to how the implant can function in the oral cavity for a long time, and the occurrence of peri- 
implant diseases is an important factor affecting the longterm effect of implant dentures. The failure of implant restoration is divided into early failure and late failure according to whether it is connected to the abutment. The former has no occlusal force load, and the latter has occlusal force load (4). The causes of the two failure types are also different: early failure is due to the formation of obstacles to the osseointegration between bone and implant, and late failure is mostly caused by peri-implant inflammation or excessive load. Generally, the early planting failure rate is higher than the late planting failure rate (5). Early failure generally refers to the loss of the implant that occurs 3-6 months after implantation and before restoration. The incidence of early implant failure is $0.7-4 \%$.

Dental implants are loose. On the one hand, it is necessary to consider the loosening of the restored crown due to poor osseointegration. In this case, it is necessary to take out the implant in time, and then implant the tooth again after the bone healing. There is another case to consider whether it is caused by local loosening of the tissue, which can be fixed by repeatedly screwing and applying force, or fixed by re-bonding, so as to reduce the loosening phenomenon. If there is a problem in the early stage of implant placement, osseointegration cannot be achieved, let alone important indicators such as later restoration and aesthetics. If we can foresee and address these early problems or take corresponding remedial measures, we can increase the success rate of planting, save time, reduce cost, and improve efficiency, and learn lessons such cases, so as to implement necessary preventive measures to reduce the occurrence of early failures (6).

Meta-analysis is conducted when a certain scientific problem needs to be solved, by formulating inclusion criteria and exclusion criteria to systematically collect related literature published globally, and screen out highquality literature that meets the requirements. Statistical methods are adopted to synthesize the research results of multiple documents, calculate the corresponding total effect, and finally yield a quantitative result (7). Compared with traditional narrative reviews, meta-analysis is more scientific and repeatable.

At present, it is recognized that the factors that may cause early implant failure include host factors, iatrogenic factors, implantation sites, and implant factors. In recent years, with the rapid advancement of materials science and surgical technology, implant failures caused by dental implants and implant surgical factors have gradually decreased. A large number of studies have focused on the effect of host factors, especially osteoporosis, radiotherapy, diabetes, and smoking among populations with the highest incidence. Smoking directly and indirectly affects oral bacteria, which may lead to changes in the functional pathways of microbial groups by changing saliva microbial groups, and then lead to diseases related to smoking. Oral microorganisms are an important part of changing the balance between oral and even systemic health and diseases. Based on modern gene high-throughput sequencing technology, more than 600 different microbial species such as bacteria, viruses, fungi, mycoplasma and chlamydia have been found on the surfaces of soft and hard tissues such as teeth, gingival sulcus, buccal tongue, soft and hard palate, which are collectively referred to as oral microbiota. The ecological imbalance of oral microflora can not only induce a variety of oral diseases, such as dental caries, periapical diseases and periodontal diseases, but also closely related to systemic diseases such as cardiovascular diseases, respiratory diseases, tumors, diabetes, rheumatoid arthritis, premature delivery and nervous system diseases. Modern studies believe that inflammation is the core mechanism of pathophysiology of many chronic systemic diseases. Oral microorganisms can spread to different parts of the body through oral mucosa and periodontal pockets through direct dissemination, blood circulation, immunization and other ways, causing systemic or local infection. Oral microbiome plays an important role in the pathogenesis of cardiovascular diseases. However, there is still very little literature on the impact of these risk factors on the treatment of dental implants, and dentists call for the use of more high-level evidence-based data to analyze it.

Therefore, this study took osteoporosis, radiotherapy, diabetes, and smoking as risk factors to systematically evaluate and meta-analyze the related research on failure of oral implant restoration treatment, and the final quantitative results provided scientific evidence-based reference for clinical oral implant restoration treatment. We present the following article in accordance with the PRISMA reporting checklist (available at https://dx.doi. org/10.21037/apm-21-3449).

\section{Methods}

\section{Literature retrieval}

Before the search, the authors read a large number of documents related to the subject of this article, conducted a preliminary search in electronic databases, and determined 
Table 1 Risk quality assessment form

\begin{tabular}{|c|c|c|c|}
\hline No. & Item & Yes & No \\
\hline 2 & Is failure of oral implants precisely defined? & 1 & 0 \\
\hline 3 & Is the lack of dental implants precisely defined? & 1 & 0 \\
\hline 4 & Does the study detail the training or background of dental implant therapists? & 1 & 0 \\
\hline 6 & Are risk factors collected using standard scales or checklists? & 1 & 0 \\
\hline 7 & Is the number of participants who withdrew or lost follow-up in each study group determined? & 1 & 0 \\
\hline 8 & Have you determined the total number of implant failure cases designated by each study group? & 1 & 0 \\
\hline 9 & Have you determined the type of implant failure in each study group? & 1 & 0 \\
\hline
\end{tabular}

the search strategy and search terms. Searches were performed in the China National Knowledge Infrastructure (CNKI) database, Baidu Academic, Weipu, Wanfang, PubMed, EBSCO, Medline, Web of knowledge, Ovid, and the Cochrane Library. The searched articles were randomized controlled trials (RCTs) taking osteoporosis, radiotherapy, diabetes, and smoking as risk factors to explore the failure of oral implant restoration treatments published from the establishment of the database to 25 June 2021. The subject words were combined freely for multiple searches to obtain all references that could be included. The search strategies included: subject terms related to research results such as survival, osseointegration, failure, removal, replacement, and loss; related to risk factors: osteoporosis, head and neck cancer, diabetes, and smoking; and oral implantology as a keyword. Then, each article was tracked with a search engine. Finally, the relevant experts and researchers who published the articles were contacted by e-mail to obtain the latest research progress.

\section{Inclusion and exclusion criteria of the articles}

Articles meeting the following conditions were included: using case-based RCTs design method, and the subject of patients with failure of oral implants.

Articles which met the following conditions were excluded: individual cases, reviews, and non-research literature; non-RTCs; articles which were published repeatedly; without available data and information; articles animal subjects and in vitro experimental research; and no mention of the data regarding relevant risk factors.

\section{Data extraction}

Uniform standards were applied whereby two evaluators extracted the authors, institutions, journals, and funding projects of the included articles, and then independently extracted the article data. The main data extracted include basic research information: title, country, name of the first author, journal of publication, and publication period; characteristics of the participants: gender, age, and number of cases; and information related to risk factors: the number and location of oral implants, and data related to implant failure.

\section{Bias risk assessment}

The risk of bias for the included RCTs was simultaneously evaluated by two reviewers, and if they encountered differences, they were resolved through discussion. This study used the internationally recognized McMaster Quality Assessment Scale of Harms (McHarm) by Holahan et al. [2008] (8) as a reference, extracted important evaluation information, developed a risk quality evaluation table that conformed to this article, and evaluated the quality of the included literature according to a score of $0-10$ points (Table 1).

\section{Statistical analysis}

The software Stata SE 12.0 (Stata Corp., College Station, TX, USA) was used for statistical analysis. This article took failure of oral implants as the final statistical research result, 
and relative risk (RR) as an evaluation indicator. The risk of bias assessment chart under RevMan 5.3 software (Cochrane Collaboration, Copenhagen, Denmark) was adopted to assess the risk bias of the included references, after sorting and filtering the data, inputting it into Rev Man 5.3 software to draw the chart. Each effect was represented by a $95 \%$ confidence interval (CI). When $\mathrm{P}>0.01$ and $\mathrm{I}^{2}<50 \%$, the fixed effects model (FEM) was used for meta-analysis. When $\mathrm{P}<0.01$ and $\mathrm{I}^{2}>50 \%$, the random effects model (REM) was used for meta-analysis.

\section{Sensitivity analysis}

The REM and the FEM were used to compare the results. According to the consistency of the results, the reliability of the combined results was analyzed and the funnel chart was drawn to determine whether there was publication bias.

\section{Results}

\section{Results of articles retrieval and the basic characteristics of included articles}

A total of 1,522 articles were retrieved from the database and 1,041 articles were obtained from the registry. After reading research titles and abstracts, 816 duplicate articles were eliminated, 425 unqualified articles were eliminated, and 87 were excluded for other reasons, leaving 1,235 articles. After full text reading screening, 526 articles were eliminated, leaving 709 articles. Among the subjects, 548 were repeatedly excluded, leaving 161. Then, 129 further articles were removed, including 76 reviews, and 53 with incomplete data indicators. Finally, 32 articles were obtained for metaanalysis. Among them, 3 articles discussed the factors of osteoporosis, 10 articles discussed the factors of radiotherapy, 3 articles discussed the factors of diabetes, and 16 articles discussed the factors of smoking. A flowchart of the literature search and screening is show in Figure 1.

There were 13 articles with a score of 8-10 (40.62\%), 15 articles with a score of $4-7(46.88 \%)$, and 4 article with a score of $0-3(12.5 \%)$. Tables $2-5$ display the basic information of literature discussing osteoporosis factors, radiotherapy factors, diabetes factors, and smoking factors, in sequence. According to the national statistics of the first author, 5 articles were from the United States; 7 articles were from Belgium; 2 articles were from the United Kingdom; 1 articles were from Australia; 5 articles were from Germany; and 1 article was from
New Zealand.

\section{Risk bias assessment of the included articles}

Among the 32 RCTs in this study, only 3 articles (13-15) described the correct random allocation method, accounting for $9.37 \%$; only 1 article (19) described in detail the concealment of the allocation plan, accounting for $3.12 \%$; and no blind method was used in the remaining articles, accounting for $87.5 \%$. The reference risk bias evaluation chart and summary chart, are shown in Figures 2,3, respectively, which were drawn using Rev Man 5.3 software.

\section{Meta-analysis results of smoking as a risk factor}

There were 16 articles (9-24) on failure of oral implants with smoking as a risk factor, with a total of 2,481 cases; there were 518 cases in the smoking group with 4,816 oral implants and there were 1,963 cases in the nonsmoking group with 8,847 oral implants. The results of the meta-analysis showed that there was a high degree of heterogeneity between smoking and failure of oral implants in the included literature $\left(\mathrm{I}^{2}=33.8 \%, \mathrm{P}=0.092\right)$, showing observable correlation ( $\mathrm{RR}=1.80,95 \% \mathrm{CI}: 1.53-2.11)$. A forest diagram of failure of oral implants in the smoking group and the non-smoking group is displayed in Figure 4.

\section{Meta-analysis results of radiotherapy as a risk factor}

There were 14 articles (9,25-37) on the influence of radiotherapy as a risk factor on failure of oral implants, with a total of 965 cases, including 310 cases in the radiotherapy group with 1,514 oral implants and 655 cases in the nonradiotherapy group with 3,266 oral implants. The results of the meta-analysis showed that there was high heterogeneity between radiotherapy and failure of oral implants in the included articles $\left(\mathrm{I}^{2}=71.6 \%, \mathrm{P}=0.000\right)$, showing visible correlation $(\mathrm{RR}=2.09,95 \% \mathrm{CI}: 1.68-2.61)$. A forest diagram of failure of oral implants in the radiotherapy group and the non-radiotherapy group is shown in Figure 5. The funnel diagram of failure of oral implants in the radiotherapy group and the non- radiotherapy group is displayed in Figure 6.

\section{Meta-analysis results of diabetes as a risk factor}

There were 3 included articles $(9,10,38)$ on failure of oral implants with diabetes as a risk factor, with a total of 


\section{Identification of studies via databases and registers}
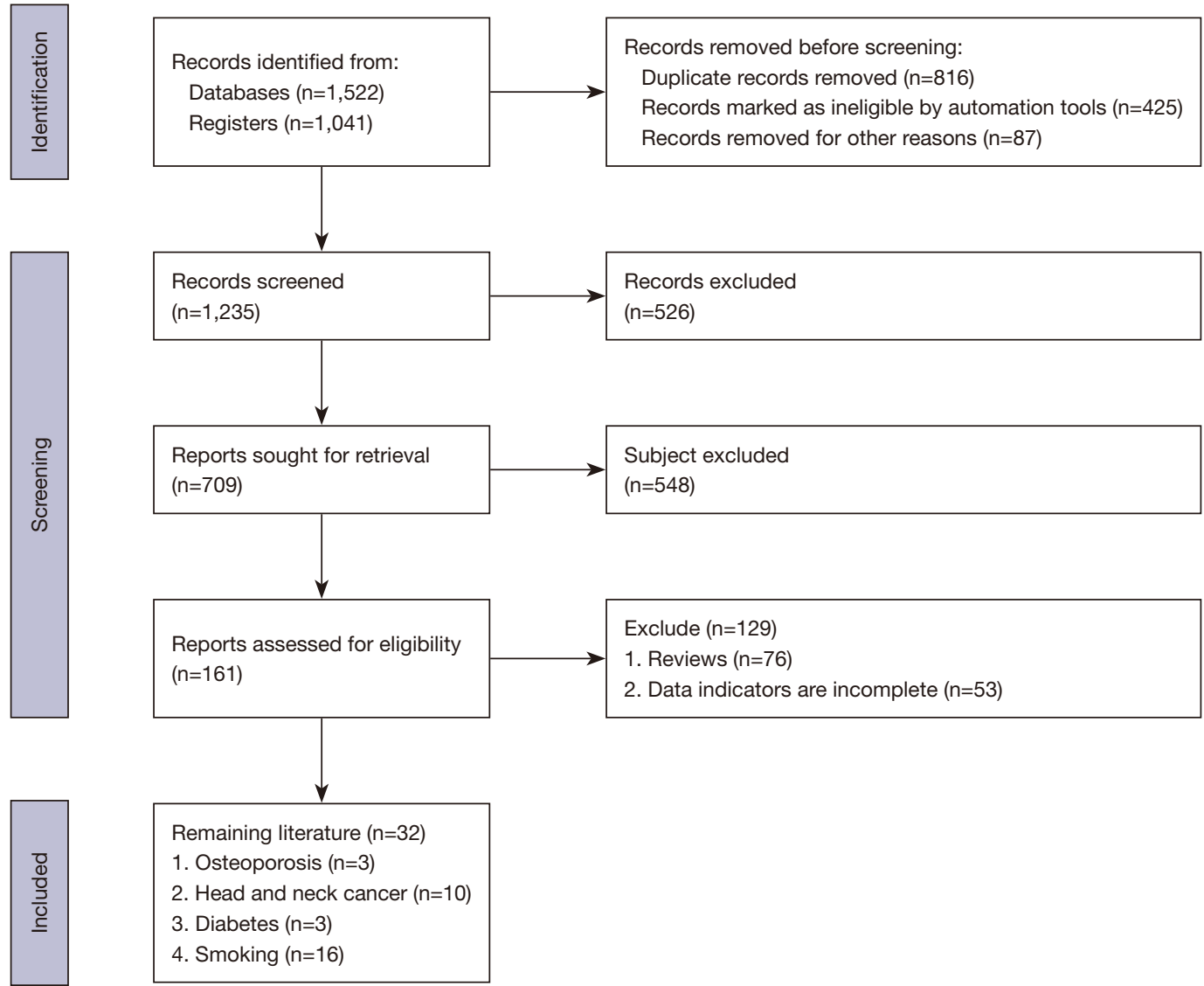

Figure 1 The entire retrieval process.

1,550 cases, including 379 cases in the diabetes group with 704 oral implants and 1,171 cases in the non-diabetic group with 2,954 oral implants. The results of the meta-analysis showed that there was heterogeneity between diabetes and failure of oral implants in the included articles $\left(\mathrm{I}^{2}=59.6 \%\right.$, $\mathrm{P}=0.084)$, showing no visible correlation $(\mathrm{RR}=0.95,95 \%$ CI: 0.64-1.41). A forest diagram of failure of oral implants in the diabetes group and the non-diabetics group is shown in Figure 7.

\section{Meta-analysis results of osteoporosis as a risk factor}

There were 3 articles $(9,39,40)$ on the influence of osteoporosis as a risk factor on failure of oral implants, with a total of 628 cases (142 cases in the osteoporosis group with 520 oral implants and 486 cases in the non- osteoporosis group with 1,877 oral implants). The metaanalysis results showed that there was a high heterogeneity between osteoporosis and failure of oral implants in the included articles $\left(\mathrm{I}^{2}=63.1 \%, \mathrm{P}=0.067\right)$, showing no remarkable correlation $(\mathrm{RR}=1.19,95 \% \mathrm{CI}: 0.81-1.74)$. A forest diagram of failure of oral implants in the osteoporosis group and the non-osteoporosis group is displayed in Figure 8. The funnel diagram of failure of oral implants in the osteoporosis group and the non-osteoporosis group is shown in Figure 9.

\section{Analysis on publication bias}

A funnel chart of the included articles is shown in Figure 10. It can be seen that the circle and the midline of the articles were basically symmetrical, indicating that the research 
Table 2 The basic information of articles discussing smoking

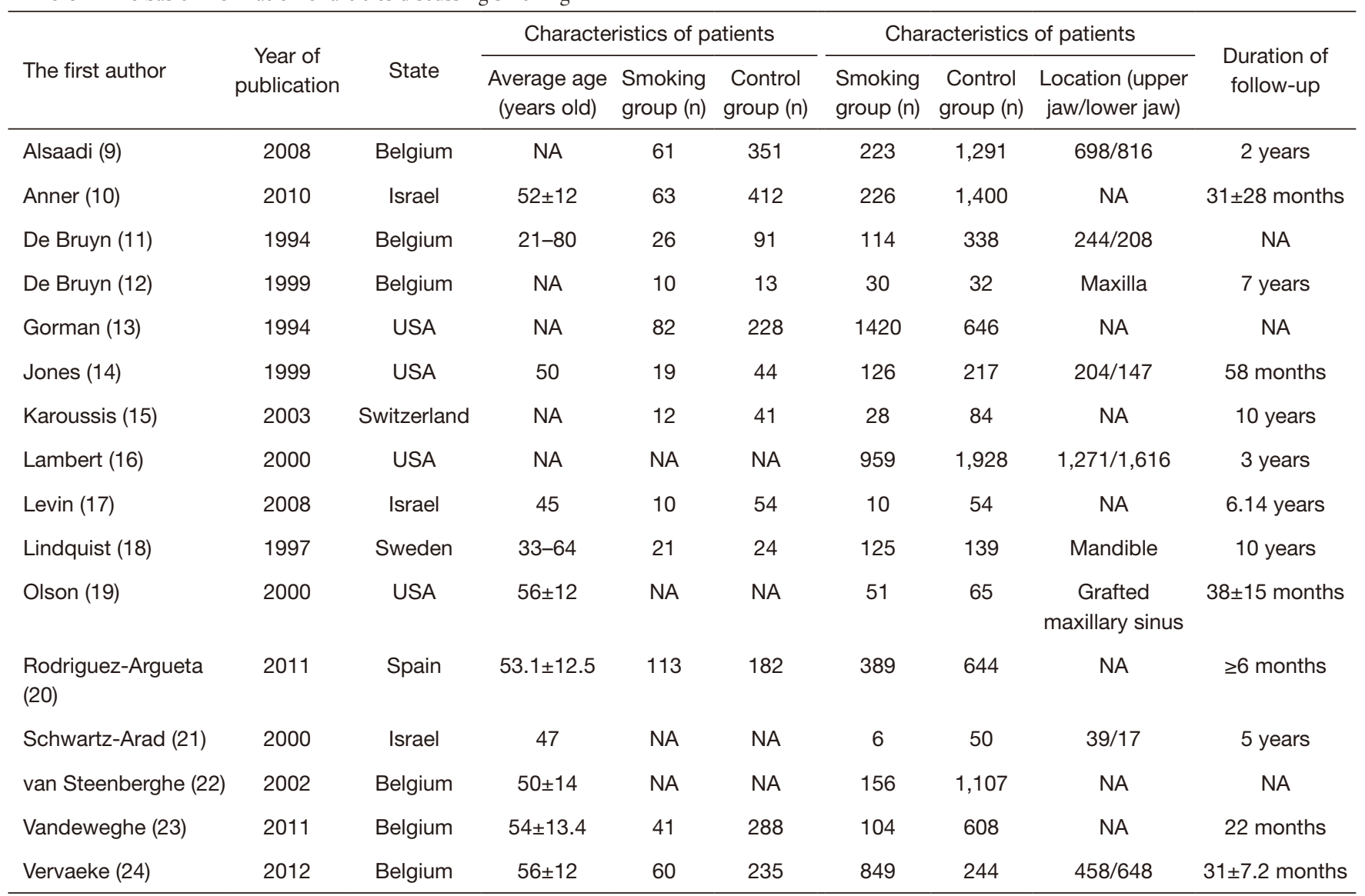

accuracy was high, there was no bias in publication, and the final conclusions obtained were more credible.

\section{Discussion}

The meta-analysis results of this study showed that there was a clear correlation between radiotherapy smoking as a risk factor and failure of oral implants. Compared with patients in the non-radiotherapy group, patients who received radiotherapy before or after oral implant surgery have a $75 \%$ probability of failure of oral implants (41-43). Studies have pointed out that the failure rate of implants implanted in bone tissues that receive radiotherapy is about 2.5 times that of ordinary bone tissues, which is similar to the results of this study (44). In addition, studies have reported that the failure rate of oral implants in the maxilla after radiotherapy is higher than that in the mandible (45). The cause may be that after the bone tissue receives radiotherapy, the cells or blood vessels located in the bone tissue receiving the radiotherapy react with the cells or blood vessels in the surrounding tissues, and the tissue metabolism changes. At present, some potential mechanisms can explain this change, including changes in the repair function of bone tissues and osteoclasts. The formation and destruction of hypoxic cell tissue and ischemic donor tissue are related to tissue perfusion capacity and tissue fibrosis. The radiotherapy dose may have a great correlation with tissue changes. Therefore, a small dose and multiple frequency method should be used in radiotherapy to reduce the damage to the human body. Auxiliary hyperoxia therapy can promote the tissue repair ability of radiotherapy, but there is no relevant research confirming that it can reduce the probability of failure of oral implants in patients.

Peri-implant inflammation is one of the important factors affecting the long-term success of implants. The diagnosis of peri-implant inflammation is the condition of the mucosa in the patient's oral cavity, and there may be redness, bleeding or slight pus overflow of the mucosa around the 


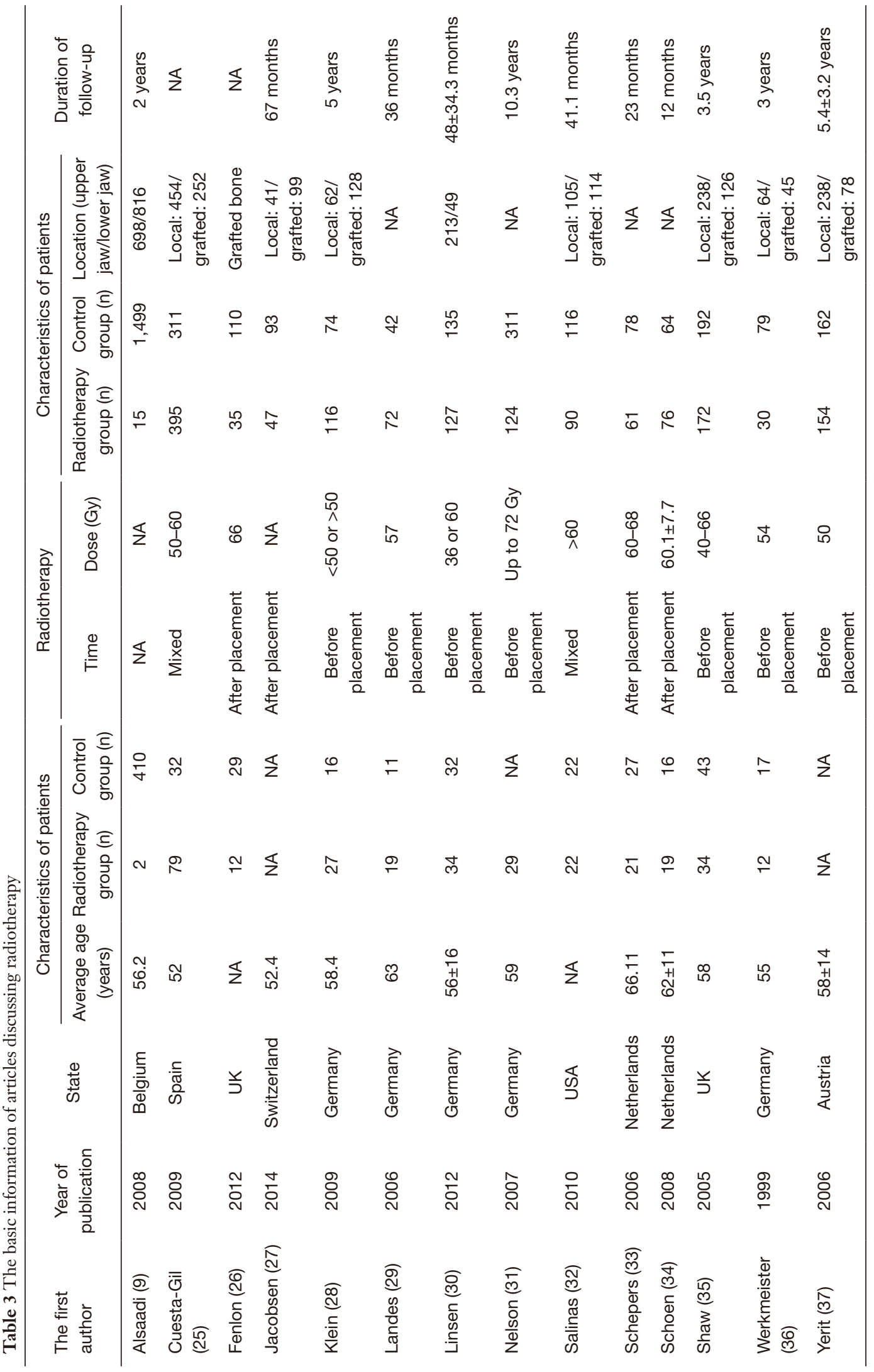


Table 4 The basic information of articles discussing diabetes

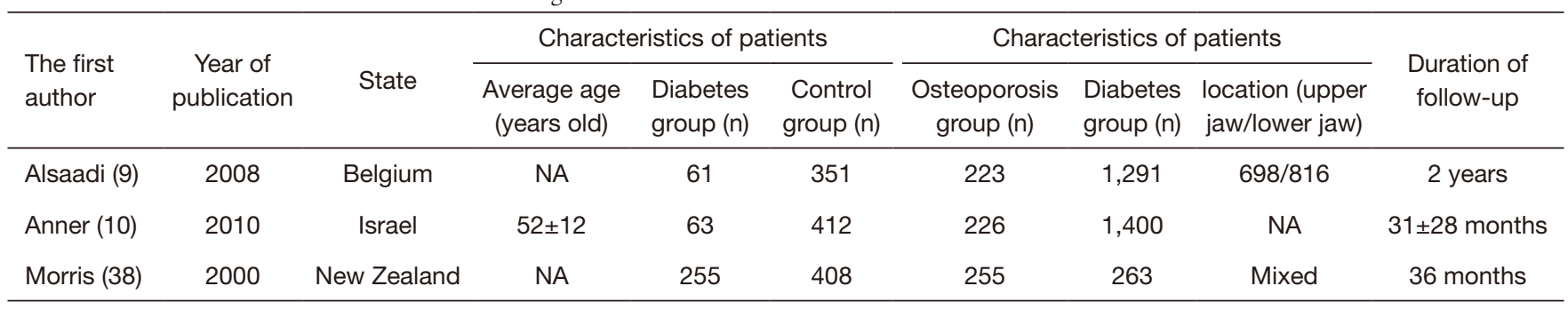

Table 5 The basic information of articles discussing osteoporosis

\begin{tabular}{|c|c|c|c|c|c|c|c|c|c|}
\hline $\begin{array}{l}\text { The first } \\
\text { author }\end{array}$ & $\begin{array}{c}\text { Year of } \\
\text { publication }\end{array}$ & State & \multicolumn{3}{|c|}{ Characteristics of patients } & \multicolumn{3}{|c|}{ Characteristics of patients } & $\begin{array}{l}\text { Duration of } \\
\text { follow-up }\end{array}$ \\
\hline Alsaadi (9) & 2008 & Belgium & NA & 61 & 351 & 223 & 1,291 & $698 / 816$ & 2 years \\
\hline Amorim (39) & 2007 & Israel & 58.2 & 19 & 20 & 39 & 43 & Mandible & 9 months \\
\hline
\end{tabular}

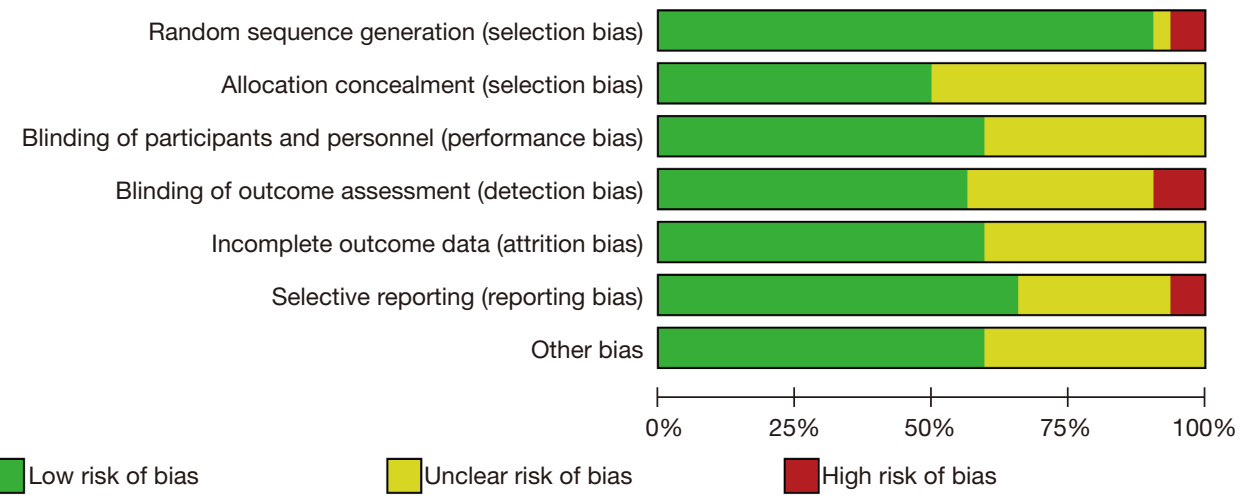

Figure 2 Assessment of risk bias of the included articles.

implant. Secondly, probe with periodontal probe to check whether the probe depth around the implant exceeds the normal limit, generally more than $4 \mathrm{~mm}$, and judge whether there is bleeding, pus overflow and fistula during probe, which is preliminarily identified as peri-implant inflammation. Then, auxiliary examination is carried out by means of radiographic film. Through radiographic examination, we can see the degree of combination between implant and alveolar bone and the degree of alveolar bone absorption. In the systematic treatment of periodontal disease, periodontal support therapy is an essential link to prevent the recurrence of periodontal disease. Similarly, it should also carry out daily maintenance for the implant week. As a periodontal support therapy, peri-implant maintenance must be made and adjusted according to the risk assessment of patients. Most of the patients undergoing implant restoration have missing teeth due to periodontitis, and their oral hygiene is usually poor. Therefore, before implant surgery, patients must be informed of the importance of self-maintenance of oral health. The speed of tissue destruction and bone resorption around implants is obviously higher than that of natural teeth. Doctors should advise patients to improve oral hygiene, maintain implants and restorations continuously and effectively, and timely report problems to doctors.

Compared with non-smoking patients, there is about 


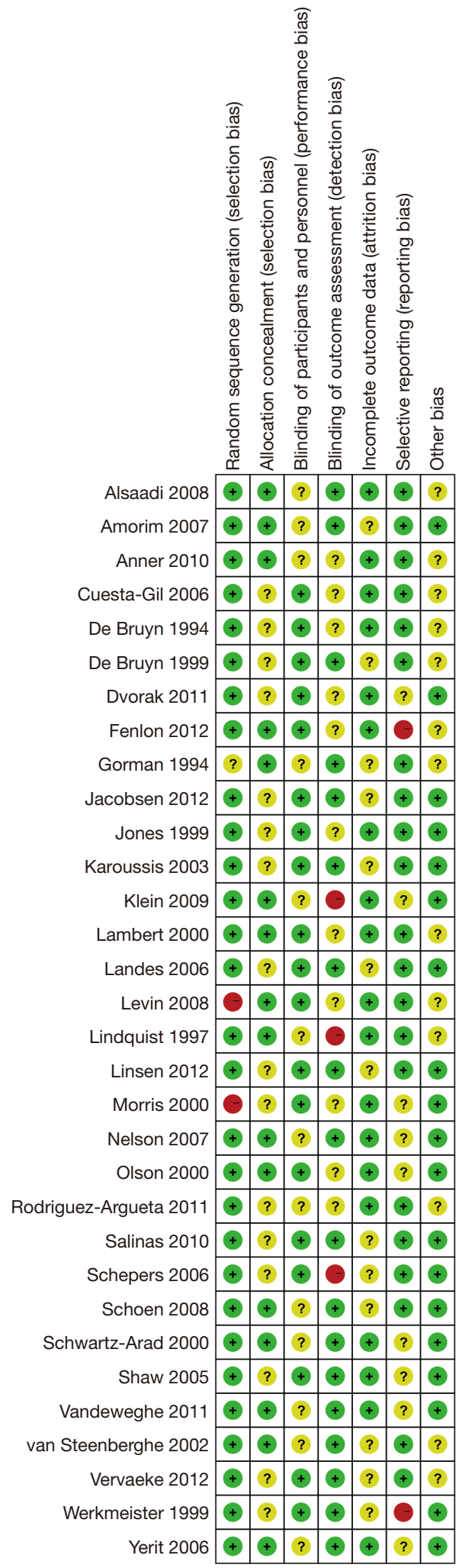

Figure 3 Multiple risk bias evaluation results of included articles. “+”, low risk; “_”, high risk; "?”, unclear.
$40 \%$ probability for smoking patients to suffer from failure of oral implants. The meta-analysis results of this study confirm that smoking populations are more likely to have failure of oral implants than non-smoking populations, which is similar to the results of Esser et al. [1997] (46). At present, there is no related article to explain the internal mechanism of the effects of smoking and failure of oral implants, but many studies have pointed out that the nicotine in tobacco can reduce the healing and repair function of oral tissues. Some researchers have suggested a ban on smoking for patients 1 week before the oral implant restoration treatment to promote the healing of oral implants, but the results show that short-term smoking ban has no effect on the probability of failure of oral implants.

This study also found no significant correlation between osteoporosis and diabetes and failure of oral implants, and osteoporosis and diabetes have a high incidence in elderly patients. Studies have reported that osteoporosis and diabetes affect the repair ability of oral tissues to a certain extent. Generally, clinical medications are used for diabetes patients, but dentists do not perform oral implant surgery on diabetes patients who are not well-controlled. The most commonly used drugs for osteoporosis are bisphosphonates, but long-term use of these drugs may cause osteonecrosis of the jaw. As osteoporosis and diabetes can be controlled by drug intervention, in the current meta-analysis, there were few studies on the correlation between the severity of osteoporosis and diabetes and failure of oral implants, which would have exerted a certain impact on the evaluation of osteoporosis and diabetes as risk factors in this study.

\section{Conclusions}

This study screened the related articles with osteoporosis, radiotherapy, diabetes, and smoking as risk factors, and compared the risk factor group and the non-risk factor group to perform a meta-analysis, aiming to explore the relevance of each risk factor to the failure of oral implant restoration treatment. The results of meta-analysis confirmed that radiotherapy and smoking was obviously correlated with failure of oral implants. However, there were some shortcomings in this study. The judgment of the confounding factors included in the study was subjective, and the interference of other risk factors could not be completely ruled out. More articles have to be included in the later period to continue to explore the combined effect of multiple factors on the failure of oral implants. In 


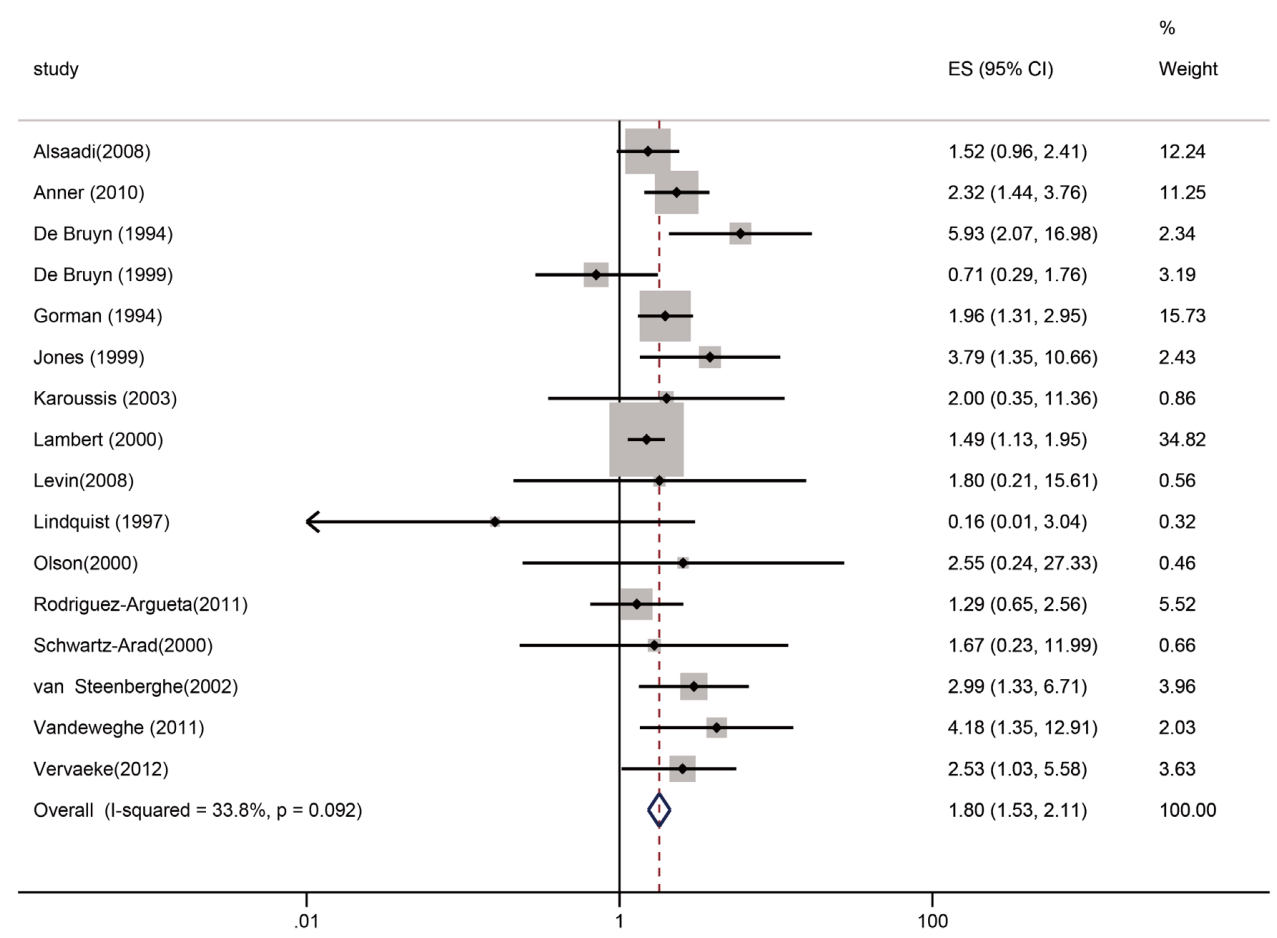

Figure 4 Forest diagram of failure of oral implants in the smoking group and the non-smoking group. ES, effect size; CI, confidence interval.

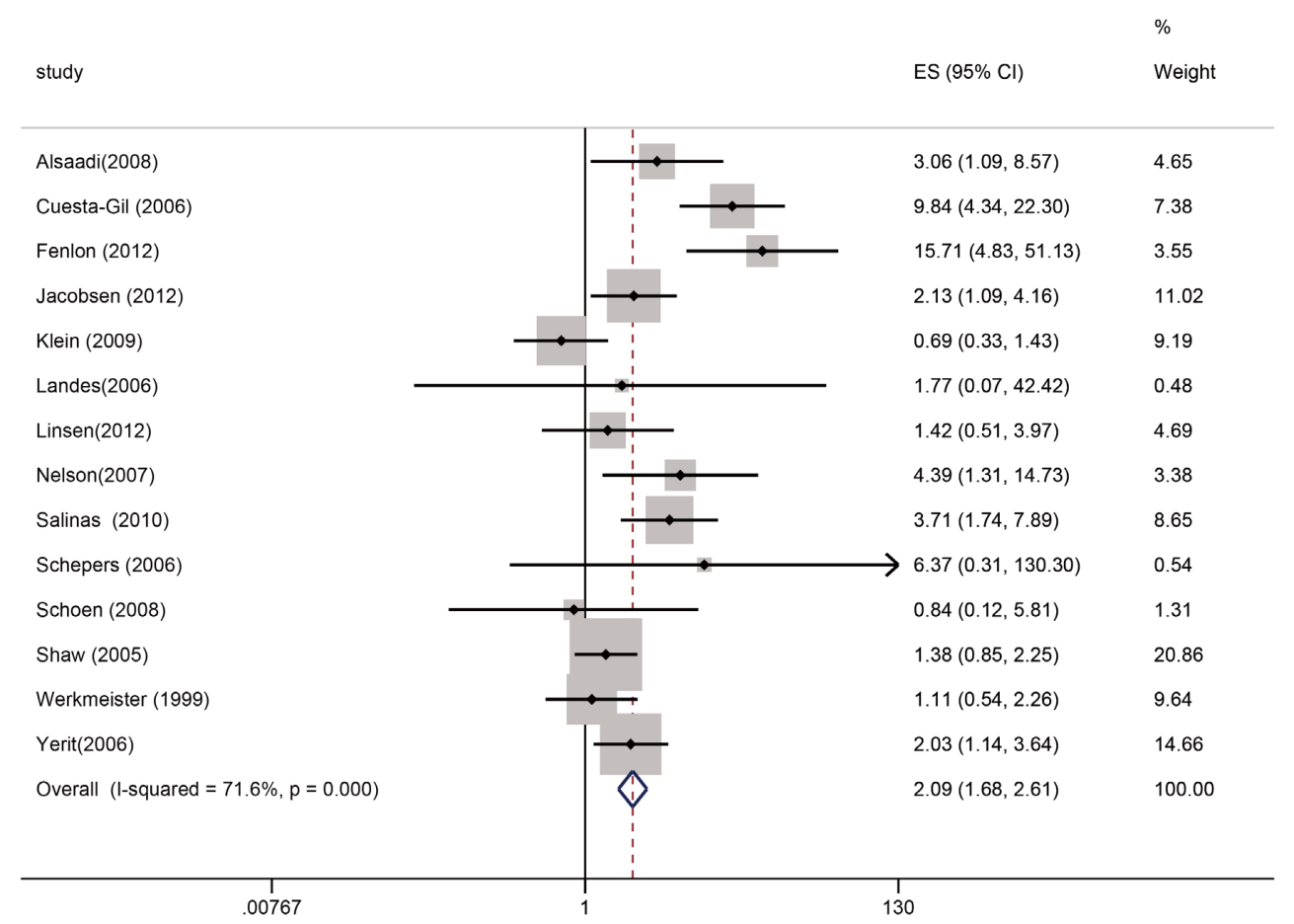

Figure 5 The forest diagram of failure of oral implants in the radiotherapy group and the non-radiotherapy group. ES, effect size; CI, confidence interval. 
Funnel plot with pseudo $95 \%$ confidence limits

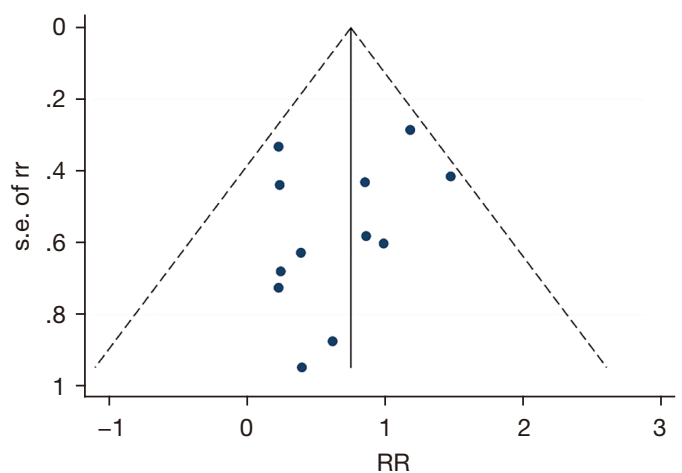

Figure 6 The funnel diagram of failure of oral implants in the radiotherapy group and the non-radiotherapy group. $R R$, relative risk.

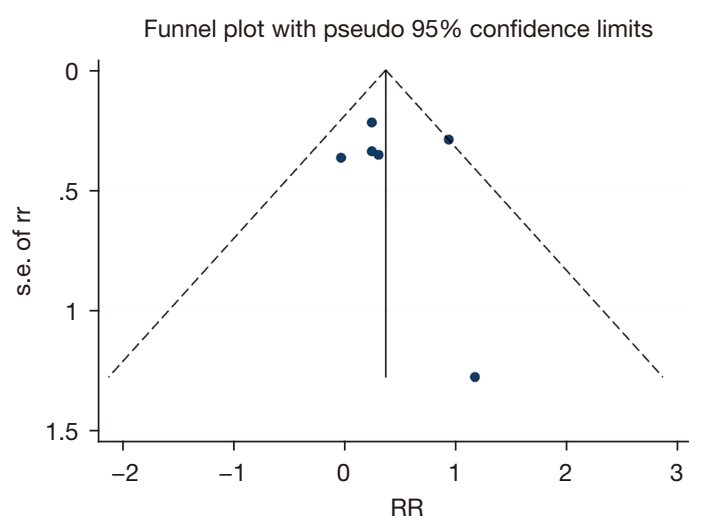

Figure 9 The funnel diagram of failure of oral implants in the osteoporosis group and the non-osteoporosis group. RR, relative risk.

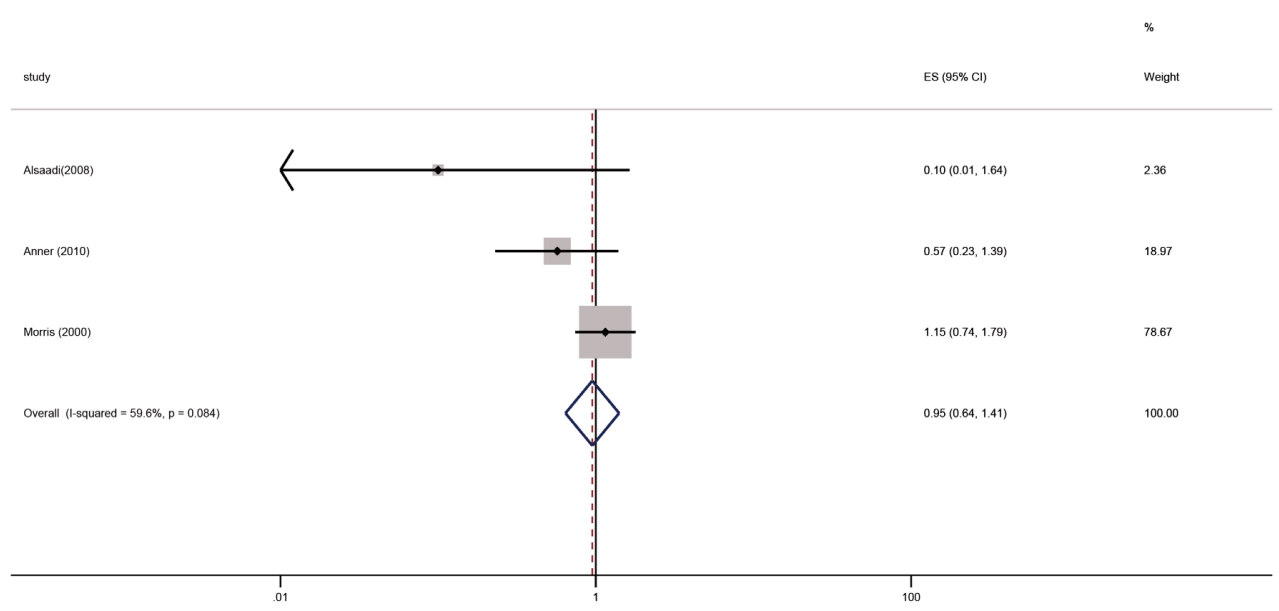

Figure 7 The forest diagram of failure of oral implants in the diabetes group and the non-diabetics group. ES, effect size; CI, confidence interval.

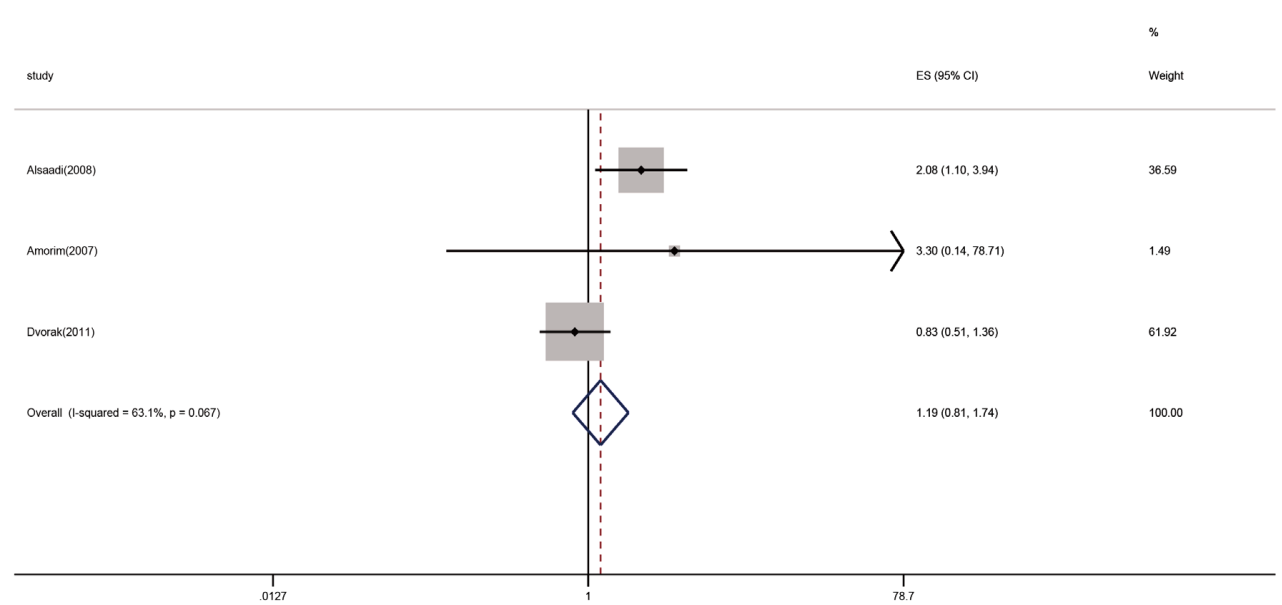

Figure 8 The forest diagram of failure of oral implants in the osteoporosis group and the non-osteoporosis group. ES, effect size; CI, confidence interval. 


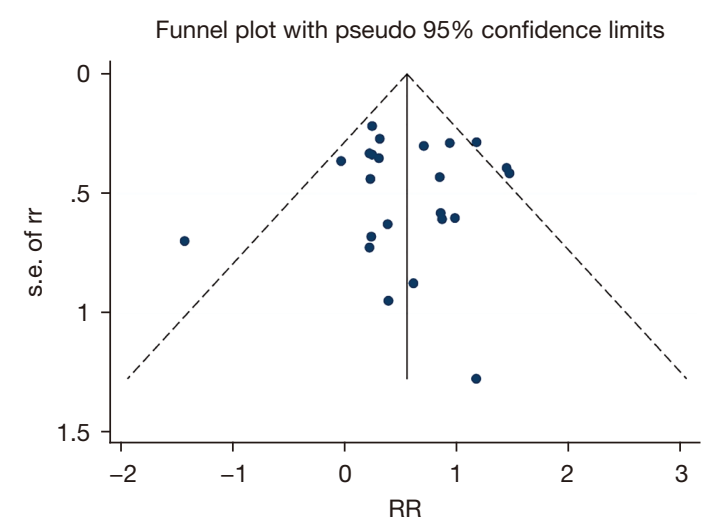

Figure 10 Funnel chart of included articles. RR, relative risk.

summary, this study provides a more reliable evidence-based basis for dental clinicians, and provides a reference for the design of later treatment plans.

\section{Acknowledgments}

Funding: None.

\section{Footnote}

Reporting Checklist: The authors have completed the PRISMA reporting checklist. Available at https://dx.doi. org/10.21037/apm-21-3449

Conflicts of Interest: All authors have completed the ICMJE uniform disclosure form (available at https://dx.doi. org/10.21037/apm-21-3449). The authors have no conflicts of interest to declare.

Ethical Statement: The authors are accountable for all aspects of the work in ensuring that questions related to the accuracy or integrity of any part of the work are appropriately investigated and resolved.

Open Access Statement: This is an Open Access article distributed in accordance with the Creative Commons Attribution-NonCommercial-NoDerivs 4.0 International License (CC BY-NC-ND 4.0), which permits the noncommercial replication and distribution of the article with the strict proviso that no changes or edits are made and the original work is properly cited (including links to both the formal publication through the relevant DOI and the license). See: https://creativecommons.org/ licenses/by-nc-nd/4.0/.

\section{References}

1. Bain CA, Moy PK. The association between the failure of dental implants and cigarette smoking. Int J Oral Maxillofac Implants 1993;8:609-15.

2. Minsk L, Polson AM, Weisgold A, et al. Outcome failures of endosseous implants from a clinical training center. Compend Contin Educ Dent 1996;17:848-50, 852-4, 856 passim.

3. Grunder U, Gaberthuel T, Boitel N, et al. Evaluating the clinical performance of the Osseotite implant: defining prosthetic predictability. Compend Contin Educ Dent 1999;20:628-40.

4. Keller EE, Tolman DE, Eckert SE. Maxillary antralnasal inlay autogenous bone graft reconstruction of compromised maxilla: a 12-year retrospective study. Int J Oral Maxillofac Implants 1999;14:707-21.

5. Geurs NC, Wang IC, Shulman LB, et al. Retrospective radiographic analysis of sinus graft and implant placement procedures from the Academy of Osseointegration Consensus Conference on Sinus Grafts. Int J Periodontics Restorative Dent 2001;21:517-23.

6. Widmark G, Andersson B, Carlsson GE, et al. Rehabilitation of patients with severely resorbed maxillae by means of implants with or without bone grafts: a 3to 5 -year follow-up clinical report. Int J Oral Maxillofac Implants 2001;16:73-9.

7. Kumar A, Jaffin RA, Berman C. The effect of smoking on achieving osseointegration of surface-modified implants: a clinical report. Int J Oral Maxillofac Implants 2002;17:816-9.

8. Holahan CM, Koka S, Kennel KA, et al. Effect of osteoporotic status on the survival of titanium dental implants. Int J Oral Maxillofac Implants 2008;23:905-10.

9. Alsaadi G, Quirynen M, Komárek A, et al. Impact of local and systemic factors on the incidence of late oral implant loss. Clin Oral Implants Res 2008;19:670-6.

10. Anner R, Grossmann Y, Anner Y, et al. Smoking, diabetes mellitus, periodontitis, and supportive periodontal treatment as factors associated with dental implant survival: a long-term retrospective evaluation of patients followed for up to 10 years. Implant Dent 2010;19:57-64.

11. De Bruyn H, Collaert B. The effect of smoking on early implant failure. Clin Oral Implants Res 1994;5:260-4.

12. De Bruyn H, Collaert B, Lindén U, et al. Clinical outcome of Screw Vent implants. A 7-year prospective follow-up 
study. Clin Oral Implants Res 1999;10:139-48.

13. Gorman LM, Lambert PM, Morris HF, et al. The effect of smoking on implant survival at second-stage surgery: DICRG Interim Report No. 5. Dental Implant CLinical Research Group. Implant Dent 1994;3:165-8.

14. Jones JD, Lupori J, Van Sickels JE, et al. A 5-year comparison of hydroxyapatite-coated titanium plasmasprayed and titanium plasma-sprayed cylinder dental implants. Oral Surg Oral Med Oral Pathol Oral Radiol Endod 1999;87:649-52.

15. Karoussis IK, Salvi GE, Heitz-Mayfield LJ, et al. Longterm implant prognosis in patients with and without a history of chronic periodontitis: a 10-year prospective cohort study of the ITI Dental Implant System. Clin Oral Implants Res 2003;14:329-39.

16. Lambert PM, Morris HF, Ochi S. The influence of smoking on 3-year clinical success of osseointegrated dental implants. Ann Periodontol 2000;5:79-89.

17. Levin L, Hertzberg R, Har-Nes S, et al. Long-term marginal bone loss around single dental implants affected by current and past smoking habits. Implant Dent 2008;17:422-9.

18. Lindquist LW, Carlsson GE, Jemt T. Association between marginal bone loss around osseointegrated mandibular implants and smoking habits: a 10-year follow-up study. J Dent Res 1997;76:1667-74.

19. Olson JW, Dent CD, Morris HF, et al. Long-term assessment (5 to 71 months) of endosseous dental implants placed in the augmented maxillary sinus. Ann Periodontol 2000;5:152-6.

20. Rodriguez-Argueta OF, Figueiredo R, ValmasedaCastellon E, et al. Postoperative complications in smoking patients treated with implants: a retrospective study. J Oral Maxillofac Surg 2011;69:2152-7.

21. Schwartz-Arad D, Grossman Y, Chaushu G. The clinical effectiveness of implants placed immediately into fresh extraction sites of molar teeth. J Periodontol 2000;71:839-44.

22. van Steenberghe D, Jacobs R, Desnyder M, et al. The relative impact of local and endogenous patient-related factors on implant failure up to the abutment stage. Clin Oral Implants Res 2002;13:617-22.

23. Vandeweghe S, De Bruyn H. The effect of smoking on early bone remodeling on surface modified Southern Implants®. Clin Implant Dent Relat Res 2011;13:206-14.

24. Vervaeke S, Collaert B, Vandeweghe S, et al. The effect of smoking on survival and bone loss of implants with a fluoride-modified surface: a 2-year retrospective analysis of
1106 implants placed in daily practice. Clin Oral Implants Res 2012;23:758-66.

25. Cuesta-Gil M, Ochandiano Caicoya S, Riba-García F, et al. Oral rehabilitation with osseointegrated implants in oncologic patients. J Oral Maxillofac Surg 2009;67:2485-96.

26. Fenlon MR, Lyons A, Farrell S, et al. Factors affecting survival and usefulness of implants placed in vascularized free composite grafts used in post-head and neck cancer reconstruction. Clin Implant Dent Relat Res 2012;14:266-72.

27. Jacobsen C, Kruse A, Lübbers HT, et al. Is mandibular reconstruction using vascularized fibula flaps and dental implants a reasonable treatment? Clin Implant Dent Relat Res 2014;16:419-28.

28. Klein MO, Grötz KA, Walter C, et al. Functional rehabilitation of mandibular continuity defects using autologous bone and dental implants - prognostic value of bone origin, radiation therapy and implant dimensions. Eur Surg Res 2009;43:269-75.

29. Landes CA, Kovács AF. Comparison of early telescope loading of non-submerged ITI implants in irradiated and non-irradiated oral cancer patients. Clin Oral Implants Res 2006;17:367-74.

30. Linsen SS, Martini M, Stark H. Long-term results of endosteal implants following radical oral cancer surgery with and without adjuvant radiation therapy. Clin Implant Dent Relat Res 2012;14:250-8.

31. Nelson K, Heberer S, Glatzer C. Survival analysis and clinical evaluation of implant-retained prostheses in oral cancer resection patients over a mean follow-up period of 10 years. J Prosthet Dent 2007;98:405-10.

32. Salinas TJ, Desa VP, Katsnelson A, et al. Clinical evaluation of implants in radiated fibula flaps. J Oral Maxillofac Surg 2010;68:524-9.

33. Schepers RH, Slagter AP, Kaanders JH, et al. Effect of postoperative radiotherapy on the functional result of implants placed during ablative surgery for oral cancer. Int J Oral Maxillofac Surg 2006;35:803-8.

34. Schoen PJ, Raghoebar GM, Bouma J, et al. Prosthodontic rehabilitation of oral function in head-neck cancer patients with dental implants placed simultaneously during ablative tumour surgery: an assessment of treatment outcomes and quality of life. Int J Oral Maxillofac Surg 2008;37:8-16.

35. Shaw RJ, Sutton AF, Cawood JI, et al. Oral rehabilitation after treatment for head and neck malignancy. Head Neck 2005;27:459-70.

36. Werkmeister R, Szulczewski D, Walteros-Benz P, et al. 
Rehabilitation with dental implants of oral cancer patients. J Craniomaxillofac Surg 1999;27:38-41.

37. Yerit KC, Posch M, Seemann M, et al. Implant survival in mandibles of irradiated oral cancer patients. Clin Oral Implants Res 2006;17:337-44.

38. Morris HF, Ochi S, Winkler S. Implant survival in patients with type 2 diabetes: placement to 36 months. Ann Periodontol 2000;5:157-65.

39. Amorim MA, Takayama L, Jorgetti V, et al. Comparative study of axial and femoral bone mineral density and parameters of mandibular bone quality in patients receiving dental implants. Osteoporos Int 2007;18:703-9.

40. Dvorak G, Arnhart C, Heuberer S, et al. Peri-implantitis and late implant failures in postmenopausal women: a cross-sectional study. J Clin Periodontol 2011;38:950-5.

41. Balshe AA, Eckert SE, Koka S, et al. The effects of smoking on the survival of smooth- and roughsurface dental implants. Int J Oral Maxillofac Implants 2008;23:1117-22.

42. Tawil G, Younan R, Azar P, et al. Conventional and

Cite this article as: Lu B, Zhang X, Liu B. A systematic review and meta-analysis on influencing factors of failure of oral implant restoration treatment. Ann Palliat Med 2021;10(12):1266412677. doi: 10.21037/apm-21-3449 advanced implant treatment in the type II diabetic patient: surgical protocol and long-term clinical results. Int J Oral Maxillofac Implants 2008;23:744-52.

43. Cavalcanti R, Oreglia F, Manfredonia MF, et al. The influence of smoking on the survival of dental implants: a 5-year pragmatic multicentre retrospective cohort study of 1727 patients. Eur J Oral Implantol 2011;4:39-45.

44. Conrad HJ, Jung J, Barczak M, et al. Retrospective cohort study of the predictors of implant failure in the posterior maxilla. Int J Oral Maxillofac Implants 2011;26:154-62.

45. Lin TH, Chen L, Cha J, et al. The effect of cigarette smoking and native bone height on dental implants placed immediately in sinuses grafted by hydraulic condensation. Int J Periodontics Restorative Dent 2012;32:255-61.

46. Esser E, Wagner W. Dental implants following radical oral cancer surgery and adjuvant radiotherapy. Int J Oral Maxillofac Implants 1997;12:552-7.

(English Language Editor: J. Jones) 